\title{
SISTEM PENDUKUNG KEPUTUSAN REKOMENDASI PEMILIHAN SMARTPHONE TERBAIK MENGGUNAKAN METODE TOPSIS
}

\author{
Anggi Eryzha', ${ }^{1}$ Solikhun²,Eka Irawan ${ }^{3}$ \\ ${ }^{123}$ Program Studi Sistem Informasi, STIKOM Tunas Bangsa, Pematangsiantar, Indonesia \\ Email: ${ }^{1}$ anggieryzha@gmail.com, ${ }^{2}$ solikhun@amiktunasbangsa.ac.id, ${ }^{3}$ eka.irawan@amiktunasbangsa.ac.id
}

\begin{abstract}
Abstrak
Smartphone merupakan kebutuhan primer bagi semua kalangan masyarakat kelas atas maupun kalangan bawah. Seiring kebutuhan tersebut banyak vendor-vendor smartphone yang menawarkan harga, fitur, sistem dan teknologi yang berbeda-beda dengan harga yang bersaing. Banyak masyarakat menginginkan spesifikasi yang mumpuni tetapi terbatas dalam hal keuangan. Hal tersebut menyebabkan pengguna smartphone tidak dapat menentukan pilihan yang tepat sesuai dengan kebutuhannya karena seringnya pemilihan smartphone didasarkan pada gengsi dan perilaku konsumtif masyarakat. Metode TOPSIS (Technique For Others Reference by Similarity To Ideal Solution) adalah metode multikriteria yang digunakan untuk mengidentifikasi solusi dari himpunan alternatif berdasarkan minimalisasi simultan dari jarak titik ideal dan memaksimalkan jarak dari titik terendah. Hasil yang diharapkan dapat menjadi masukan kepada calon pembeli smartphone yang sesuai dengan keuangannya dan spesifikasi yang mumpuni.
\end{abstract}

Kata Kunci: Sistem Pendukung Keputusan, Metode Topsis, Smartphone.

\begin{abstract}
Smartphones are a primary need for all upper class and lower class people. As these needs are many smartphone vendors that offer different prices, features, systems and technologies at competitive prices. Many people want specifications that are capable but limited in financial terms. This causes smartphone users not to be able to make the right choice according to their needs because the frequent selection of smartphones is based on prestige and consumer consumptive behavior. The TOPSIS method is a multicriteria method used to identify solutions from alternative sets based on simultaneous minimization of the ideal point distance and maximizing the distance from the lowest point. The expected results can be input to potential smartphone buyers in accordance with their finances and qualified specifications.
\end{abstract}

Keywords: Decision Support System, Topsis Method, Smartphone.

\section{PENDAHULUAN}

Perkembangan smartphone yang begitu pesat, membuat daya beli masyarakat semakin tinggi dengan kriteriakriteria yang ada, mulai dari merek, harga sampai dengan fitur-fiturnya yang harus dipertimbangkan calon pembeli dalam membeli smartphone. Masyarakat cenderung memilih smartphone dengan harga yang relatif murah dan memiliki spesifikasi yang bagus. Kebutuhan masyarakat akan smartphone untuk memenuhi berbagai kebutuhan sehari-hari seperti chatting, browsing, berselancar di sosial media, bermain game, maupun dalam melakukan bisnis, baik bisnis rumahan maupun bisnis perusahaaan, tentunya membutuhkan jenis smartphone yang berbeda-beda sesuai dengan keinginan, kegunaan, dan anggarannya. Hal ini tentu membingungkan dan menyulitkan konsumen khususnya dikalangan remaja dalam menentukan smartphone yang akan dibeli. Salah satu solusinya adalah dengan Sistem Pendukung Keputusan yang memudahkan konsumen untuk mendapatkan smartphone dengan kualitas terbaik berdasarkan keinginan, kegunaan, dan anggarannya. Metode yang digunakan dalam pengambilan keputusan pemilihan smartphone ini dengan menggunakan metode TOPSIS. Metode ini dipilih karena mampu memilih alternatif terbaik dari sejumlah alternatif, dalam hal ini alternatif yang dimaksud adalah smartphone terbaik berdasarkan kriteria-kriteria yang telah ditentukan. Hasil dari proses pengimplementasian metode TOPSIS dapat mengurutkan alternatif dari nilai yang terbesar ke nilai yang terkecil. Selain itu sistem ini dibangun dengan basis web, sehingga hal ini sangat berguna bagi konsumen dalam menemukan informasi pemilihan smartphone tanpa harus dibatasi oleh ruang dan waktu. Dengan adanya sistem pendukung keputusan ini diharapkan para konsumen dapat memiliki panduan dalam pemilihan smartphone.

\section{TEORITIS}

\subsection{Sistem Pendukung Keputusan (SPK)}

Sistem pendukung keputusan merupakan sistem informasi interaktif yang menyediakan informasi, pemodelan, dan pemanipulasian data. Sistem itu digunakan untuk membantu keputusan dalam situasi yang semiterstruktur dan situasi yang tidak terstruktur, dimana tak seorang pun tahu secara pasti bagaimana keputusan seharusnya dibuat. Sistem pendukung keputusan biasanya dibangun untuk mendukung solusi atas suatu masalah atau untuk mengevaluasi suatu peluang. [1].

\subsection{MCDM}

Multiple Criteria Decision Making (MCDM) merupakan suatu metode pengambilan keputusan yang didasarkan atas teori-teori, proses-proses, dan metode analitik yang melibatkan ketidakpastian, dinamika, dan aspek kriteria 
jamak. Dalam metode optimasi konvensional, cakupan umumnya hanya dibatasi pada satu kriteria pemilihan (mono kriteria), dimana pemilihan yang diambil adalah pilihan yang paling memenuhi fungsi obyektif. Akan tetapi masalah yang dihadapi khususnya yang lebih bersifat praktis tidaklah sesederhana itu. Ada kalanya pertimbanganpertimbangan subjektif harus dimasukkan ke dalam proses pembuatan keputusan. Kondisi ini menyebabkan pendekatan optimasi konvensional tidak lagi dapat dipergunakan [2].

\subsection{TOPSIS}

TOPSIS (Technique for Order Preference by Similarity to Ideal Solution) adalah salah satu metode pengambilan keputusan multikriteria yang pertama kali diperkenalkan oleh Yoon dan Hwang. Topsis menggunakan prinsip bahwa alternatif yang terpilih harus mempunyai jarak terdekat dari solusi ideal positif dan jarak terpanjang (terjauh) dari solusi ideal negatif dari sudut pandang geometris dengan menggunakan jarak Euclidean (jarak antara dua titik) untuk menentukan kedekatan relatif dari suatu alternatif dengan solusi optimal [3]. Berikut ini langkah-langkah algoritma dari metode Topsis: [4]

1. Menggambarkan alternatif (m) dan kriteria (n) ke dalam sebuah matriks keputusan (D), Dengan Xij menyatakan performansi dari perhitungan untuk alternatif ke-i terhadap kriteria ke-j. Matriks ini dapat dilihat pada persamaan (1) berikut :

$D=\left[\begin{array}{lll}X_{11} & X_{12 . .} & X_{1 n} \\ X_{21} & X_{22 . .} & X_{2 n} \\ X_{m 1} & X_{m 2 . .} & X_{m n}\end{array}\right]$

dimana $\mathrm{m}=$ jumlah alternatif yang ada; $\mathrm{n}=$ jumlah kriteria yang ada

2. Membuat matriks R yaitu matriks keputusan ternormalisasi dengan perhitungan menggunakan persamaan (2):

$$
\begin{aligned}
& R=\left[\begin{array}{lll}
r_{11} & r_{12 . .} & r_{1 n} \\
r_{21} & r_{22 . .} & r_{2 n} \\
r_{i 1} & r_{i 2 . .} & r_{i j}
\end{array}\right] \\
& r_{i j}=\frac{X_{i j}}{\sqrt{\sum_{i=1}^{m} X_{i j}^{2}}}
\end{aligned}
$$

Jika rumus diatas diturunkan

$r_{11}=\frac{X_{11}}{\sqrt{X_{11}^{2}+X_{21}^{2}+\cdots+X_{m i}^{2}}}$

Dimana :

rij adalah elemen dari matriks keputusan ternormalisasi (R)

xij adalah elemen dari matriks keputusan (D)dengan $i=1,2,3 \ldots . . m$; dan $j=1,2,3$. ....n.

3. Membangun matrik keputusan ternormalisasi dengan bobot (Y), yang elemen-elemen matriksnya dapat dihitung dengan persamaan(3) berikut:

$$
\begin{aligned}
& Y_{i j}=W_{j} r_{i j} \\
& Y=\left[\begin{array}{llc}
w_{1} r_{11} & w_{2} r_{12} & w_{j} r_{i j} \\
w_{1} r_{21} & \ldots & \ldots \\
w_{1} r_{i 1} & w_{2} r_{i 2} & w_{j} r_{i j}
\end{array}\right]
\end{aligned}
$$

Yij adalah elemen dari matriks keputusan ternormalisasi terbobot (Y)

dengan $\mathrm{i}=1,2,3 \ldots . . \mathrm{m}$; dan $\mathrm{j}=1,2,3$....n.

4. Menghitung matriks solusi ideal positif $(\mathrm{A}+)$ dan matriks solusi ideal negatif (A-) berdasarkan rating bobot ternormalisasi di poin tiga. Perlu diperhatikan bahwa agar dapat menghitung solusi ideal negatif atau positif, harus di bedakan antara mana yang bersifat keuntungan dan mana yang bersifat biaya dengan persamaan (4) berikut :
$A+=(y 1+, 2+, \ldots . ., y n+)$
$A-=(y 1-, 2-, \ldots ., y n-)$
Dimana, $A j+$ adalah :
- max Yij, jika j adalah kriteria keuntungan
- min Y ij, jika j adalah kriteria biaya
$A j-$ adalah :
- min Yij, jika j adalah kriteria keuntungan
- max Yij, jika j adalah kriteria biaya

5. Menghitung jarak antara nilai setiap alternatif dengan matriks solusi ideal positif (separasi positif) dan matriks solusi ideal negatif (seperasi negatif). Jarak antara alternatif Ai dengan solusi ideal positif dirumuskan dengan persamaan (5) sebagai berikut: 
$S_{i}^{+}=\sqrt{\sum_{j=1}^{n}\left(Y_{j}^{+}-Y_{i j}\right)^{2}}$

dimana $\mathrm{i}=1,2,3, \ldots \mathrm{m}$

Jarak antara alternatif Ai dengan solusi ideal negatif dirumuskan dengan persamaan (7) sebagai berikut :

$S_{i}^{-}=\sqrt{\sum_{j=1}^{n}\left(Y_{i j}-Y_{j}^{-}\right) 2}$

dimana $\mathrm{i}=1,2,3, \ldots \mathrm{m}$

6. Menghitung nilai preferensi untuk setiap alternatif Nilai preferensi untuk setiap alternatif (Vi) dapat dihitung dengan persamaan (8) ini :

$V i=\frac{D_{i}^{-}}{D_{i}^{-}+D_{i}^{+}}$

dimana $i=1,2,3, \ldots \mathrm{m}$

Nilai Vi yang lebih besar menunjukkan bahwa alternatif Ai lebih dipilih.

\subsection{Teknik Pengumpulan Data}

Penelitian ini menggunakan Kuesioner yang dilakukan dengan melakukan pengumpulan data atau informasi kepada pihak yang mengisi pernyataan atau pertanyaan yang diberikan. Penulis memberikan kuesioner kepada konsumen khususnya kalangan remaja Toko PAJAK HP Pematangsiantar sesuai dengan kasus yang diangkat penulis.

\section{ANALISA DAN PEMBAHASAN}

\subsection{Proses Perhitungan}

Pada tahap ini adalah proses perhitungan manual dengan menggunakan rumus Metode TOPSIS. penulis menentukan rekomendasi smartphone terbaik berdasarkan Merk dan Harga. Algoritma TOPSIS digunakan untuk pengambilan keputusan berdasarkan Nilai Preferensi sebagai Perankingan. Dalam kasus ini peneliti menggunakan contoh perhitungan menggunakan Merk Samsung dan Harga $<=2$ Juta. Berikut ini langkah-langkah dalam mencari smartphone terbaik dengan menggunakan Algoritma TOPSIS :

Tabel 1. Matriks Keputusan

\begin{tabular}{ccccccccc}
\hline \multirow{2}{*}{ Alternatif } & \multicolumn{8}{c}{ Kriteria } \\
\cline { 2 - 9 } & C1 & C2 & C3 & C4 & C5 & C6 & C7 & C8 \\
\hline A1 & 1 & 1 & 1 & 1 & 3 & 2 & 2 & 1 \\
A2 & 1 & 1 & 2 & 3 & 3 & 5 & 3 & 3 \\
A3 & 2 & 1 & 2 & 3 & 3 & 3 & 3 & 3 \\
A4 & 2 & 3 & 3 & 3 & 3 & 5 & 3 & 4 \\
\hline
\end{tabular}

Dimana :

$\mathrm{A}_{\mathrm{i}}=$ Alternatif

$\mathrm{C}_{\mathrm{j}}=$ Ram (C1), Memori Internal (C2), Kamera Belakang (C3), Kamera Depan (C4), Prosesor (C5), OS (C6), Baterai (C7), dan Ukuran Layar (C8).

Langkah 1: Membangun Normalized Decision Matrix (Matriks Keputusan Ternomalisasi)

Diperoleh dengan menggunakan rumus (2) :

$$
\begin{aligned}
& \mathrm{X} 1=\sqrt{1^{2}+1^{2}+2^{2}+2^{2}}=3,1623 \\
& \mathrm{R} 11=\frac{X 11}{X 1}=\frac{1}{3,1623}=0,3162 \\
& \mathrm{R} 21=\frac{X 11}{X 1}=\frac{1}{3,1623}=0,3162 \\
& \mathrm{R} 31=\frac{X 11}{X 1}=\frac{2}{3,1623}=0,6325 \\
& \mathrm{R} 41=\frac{X 11}{X 1}=\frac{2}{3,1623}=0,6325
\end{aligned}
$$

Begitu seterusnya hingga R48, dan hasil selengkapnya dapat dilhat pada Tabel 2 berikut :

Tabel 2. Matriks Keputusan Ternormalisasi

\begin{tabular}{llllllll}
\hline X1 & $\mathbf{3 , 1 6 2 3}$ & X2 & $\mathbf{3 , 4 6 4 1}$ & $\mathbf{X 3}$ & $\mathbf{4 , 2 4 2 6}$ & $\mathbf{X 4}$ & $\mathbf{5 , 2 9 1 5}$ \\
\hline R11 & 0,3162 & R12 & 0,2887 & R13 & 0,2357 & R14 & 0,1890 \\
R21 & 0,3162 & R22 & 0,2887 & R23 & 0,4714 & R24 & 0,5669 \\
R31 & 0,6325 & R32 & 0,2887 & R33 & 0,4714 & R34 & 0,5669 \\
R41 & 0,6325 & R42 & 0,8660 & R43 & 0,7071 & R44 & 0,5669 \\
& & & & & & & \\
\hline X5 & $\mathbf{6 , 0 0 0 0}$ & X6 & $\mathbf{7 , 9 3 7 3}$ & X7 & $\mathbf{5 , 5 6 7 8}$ & X8 & $\mathbf{5 , 9 1 6 1}$ \\
\hline R15 & 0,5000 & R16 & 0,2520 & R17 & 0,3592 & R18 & 0,1690 \\
\hline
\end{tabular}




\begin{tabular}{llllllll}
\hline R25 & 0,5000 & R26 & 0,6299 & R27 & 0,5388 & R28 & 0,5071 \\
R35 & 0,5000 & R36 & 0,3780 & R37 & 0,5388 & R38 & 0,5071 \\
R45 & 0,5000 & R46 & 0,6299 & R47 & 0,5388 & R48 & 0,6761 \\
\hline
\end{tabular}

Langkah 2 : Menghitung Bobot Ternormalisasi

Menyusun matriks ternormalisasi terbobot dengan perkalian Normalisasi dan Bobot Preferensi. Bobot Preferensi dapat dilihat pada Tabel 3 berikut :

Tabel 3. Bobot Preferensi

\begin{tabular}{ll}
\hline Bobot & Nilai \\
\hline C1=RAM & 0,2 \\
C2=Memori Internal & 0,2 \\
C3=Kamera Belakang & 0,1 \\
C4=Kamera Depan & 0,1 \\
C5=Prosesor & 0,15 \\
C6=OS & 0,1 \\
C7=Baterai & 0,1 \\
C8=Ukuran Layar & 0,05 \\
\hline
\end{tabular}

Sehingga perhitungan $\mathrm{y}_{\mathrm{ij}}$ dapat dilihat pada tabel 4 sebagai berikut:

Tabel 4. Perhitungan Matriks Ternormalisasi Terbobot

\begin{tabular}{|c|c|c|c|c|c|c|c|}
\hline 0,3162 & 0,2887 & 0,2357 & 0,1890 & 0,5000 & 0,2520 & 0,3592 & 0,1690 \\
\hline $\mathrm{X}$ & $\mathrm{X}$ & $\mathrm{X}$ & $\mathrm{X}$ & $\mathrm{X}$ & $\mathrm{X}$ & $\mathrm{X}$ & $\mathrm{X}$ \\
\hline 0,2 & 0,2 & 0,1 & 0,1 & 0,15 & 0,1 & 0,1 & 0,05 \\
\hline 0,3162 & 0,2887 & 0,4714 & 0,5699 & 0,5000 & 0,6299 & 0,5388 & 0,5071 \\
\hline $\mathrm{X}$ & $\mathrm{x}$ & $\mathrm{X}$ & $\mathrm{X}$ & $\mathrm{X}$ & $\mathrm{X}$ & $\mathrm{X}$ & $\mathrm{X}$ \\
\hline 0,2 & 0,2 & 0,1 & 0,1 & 0,15 & 0,1 & 0,1 & 0,05 \\
\hline 0,6325 & 0,2887 & 0,4714 & 0,5699 & 0,5000 & 0,3780 & 0,5388 & 0,5071 \\
\hline $\mathrm{x}$ & $\mathrm{X}$ & $\mathrm{x}$ & $\mathrm{X}$ & $\mathrm{X}$ & $\mathrm{X}$ & $\mathrm{x}$ & $\mathrm{X}$ \\
\hline 0,2 & 0,2 & 0,1 & 0,1 & 0,15 & 0,1 & 0,1 & 0,05 \\
\hline 0,6325 & 0,8660 & 0,7071 & 0,5699 & 0,5000 & 0,6299 & 0,5388 & 0,5071 \\
\hline $\mathrm{x}$ & $\mathrm{x}$ & $\mathrm{X}$ & $\mathrm{X}$ & $\mathrm{X}$ & $\mathrm{x}$ & $\mathrm{x}$ & $\mathrm{x}$ \\
\hline 0,2 & 0,2 & 0,1 & 0,1 & 0,15 & 0,1 & 0,1 & 0,05 \\
\hline
\end{tabular}

Hasil $\mathrm{y}_{\mathrm{ij}}$ dapat dilihat sebagai berikut:

$\left\{\begin{array}{llllllll}0,0632 & 0,0577 & 0,0236 & 0,0189 & 0,0750 & 0,0252 & 0,0539 & 0,0085 \\ 0,0632 & 0,0577 & 0,0471 & 0,0567 & 0,0750 & 0,0630 & 0,0539 & 0,0254 \\ 0,1265 & 0,0577 & 0,0471 & 0,0567 & 0,0750 & 0,0378 & 0,0539 & 0,0254 \\ 0,1265 & 0,1732 & 0,0707 & 0,0567 & 0,0750 & 0,0630 & 0,0539 & 0,0338\end{array}\right\}$

\section{Langkah 3: Menentukan Matriks Solusi Ideal Positif dan Matriks Solusi Ideal Negatif}

Solusi ideal positif $\mathrm{A}^{+}$dan solusi ideal negative $\mathrm{A}^{-}$dapat ditentukan berdasarkan rating bobot ternormalisasi $\mathrm{y}_{\mathrm{ij}}$ dengan menggunakan rumus (4) dan (5). Sehingga diperoleh :

$\mathrm{y}_{1}{ }^{+}=\operatorname{Max}(0,0632 ; 0,0632 ; 0,1265 ; 0,1265)=0,1265$

$\mathrm{y}_{2}^{+}=\operatorname{Max}(0,0577 ; 0,0577 ; 0,0577 ; 0,1732)=0,1732$

$\mathrm{y}_{7}^{+}=\operatorname{Max}(0,0359 ; 0,0539 ; 0,0539 ; 0,0539)=0,0539$

$\mathrm{y}_{8}{ }^{+}=\operatorname{Max}(0,0085 ; 0,0254 ; 0,0254 ; 0,0338)=0,0338$

Sehingga $\mathrm{A}^{+}=(0,1265 ; 0,1732 ; 0,0707 ; 0,0567 ; 0,0750 ; 0,0630 ; 0,0539 ; 0,0338)$

$\mathrm{y}_{1}{ }^{-}=\operatorname{Min}(0,0632 ; 0,0632 ; 0,1265 ; 0,1265)=0,0632$

$\mathrm{y}_{2}{ }^{-}=\operatorname{Min}(0,0577 ; 0,0577 ; 0,0577 ; 0,1732)=0,0577$

$\mathrm{y}_{7}^{-}=\operatorname{Min}(0,0359 ; 0,0539 ; 0,0539 ; 0,0539)=0,0359$

$\mathrm{y}_{8}{ }^{-}=\operatorname{Min}(0,0085 ; 0,0254 ; 0,0254 ; 0,0338)=0,0085$

Sehingga $A^{-}=(0,0632 ; 0,0577 ; 0,0236 ; 0,0189 ; 0,0750 ; 0,0252 ; 0,0359 ; 0,0085)$

Langkah 4 : Menentukan jarak antara nilai setiap alternatif dengan matriks solusi ideal positif dan matriks solusi ideal negatif

Menentukan separation measures atau jarak setiap alternatif terhadap titik ideal positif dan titik ideal negatif. Untuk menghitung jarak setiap alternatif terhadap ideal positif dan negatif menggunakan rumus (6) dan (7). Untuk jarak ideal positif sebagai berikut : 
$\mathrm{D} 1^{+}=\sqrt{\begin{array}{l}(0,0632-0,1265)^{2}+(0,0577-0,1732)^{2}+(0,0236-0,0707)^{2}+(0,0189-0,0567)^{2} \\ +(0,0750-0,0750)^{2}+(0,0252-0,0630)^{2}+(0,0359-0,0539)^{2}+(0,0085-0,0338)^{2}\end{array}}$

$=0,1529$

$\mathrm{D}^{+}=\sqrt{\begin{array}{c}(0,0632-0,1265)^{2}+(0,0577-0,1732)^{2}+(0,0471-0,0707)^{2}+(0,0567-0,0567)^{2} \\ +(0,0750-0,0750)^{2}+(0,0630-0,0630)^{2}+(0,0539-0,0539)^{2}+(0,0254-0,0338)^{2}\end{array}}$

$=0,1340$

$\mathrm{D} 3^{+}=\sqrt{\begin{array}{l}(0,1265-0,1265)^{2}+(0,0577-0,1732)^{2}+(0,0471-0,0707)^{2}+(0,0567-0,0567)^{2} \\ +(0,0750-0,0750)^{2}+(0,0378-0,0630)^{2}+(0,0539-0,0539)^{2}+(0,0254-0,0338)^{2}\end{array}}$

$=0,1280$

$\mathrm{D} 4^{+}=\sqrt{\begin{array}{c}(0,1265-0,1265)^{2}+(0,1732-0,1732)^{2}+(0,0707-0,0707)^{2}+(0,0567-0,0567)^{2} \\ +(0,0750-0,0750)^{2}+(0,0630-0,0630)^{2}+(0,0539-0,0539)^{2}+(0,0338-0,0338)^{2}\end{array}}$

$=0$

Untuk jarak ideal negatif sebagai berikut :

$\mathrm{D}^{-}=\sqrt{\begin{array}{l}(0,0632-0,0632)^{2}+(0,0577-0,0577)^{2}+(0,0236-0,0236)^{2}+(0,0189-0,0189)^{2} \\ +(0,0750-0,0750)^{2}+(0,0252-0,0252)^{2}+(0,0359-0,0359)^{2}+(0,0085-0,0085)^{2}\end{array}}$

$=0$

D2 $=\sqrt{\begin{array}{l}(0,0632-0,0632)^{2}+(0,0577-0,0577)^{2}+(0,0471-0,0236)^{2}+(0,0567-0,0189)^{2} \\ +(0,0750-0,0750)^{2}+(0,0630-0,0252)^{2}+(0,0539-0,0359)^{2}+(0,0254-0,0085)^{2}\end{array}}$

$=0,0634$

D3 $=\sqrt{\begin{array}{l}(0,1265-0,0632)^{2}+(0,0577-0,0577)^{2}+(0,0471-0,0236)^{2}+(0,0567-0,0189)^{2} \\ +(0,0750-0,0750)^{2}+(0,0378-0,0252)^{2}+(0,0539-0,0359)^{2}+(0,0254-0,0085)^{2}\end{array}}$

$=0,0822$

$\mathrm{D}^{-}=\sqrt{\begin{array}{l}(0,1265-0,0632)^{2}+(0,1732-0,0577)^{2}+(0,0707-0,0236)^{2}+(0,0567-0,0189)^{2} \\ +(0,0750-0,0750)^{2}+(0,0630-0,0252)^{2}+(0,0539-0,0359)^{2}+(0,0338-0,0085)^{2}\end{array}}$ $=0,1529$

Tabel 5. Jarak solusi ideal positif dan negatif

\begin{tabular}{lll}
\hline $\mathbf{A}_{\mathbf{i}}$ & $\mathbf{D +}$ & $\mathbf{D}-$ \\
\hline A1 & 0,1529 & 0,0000 \\
A2 & 0,1340 & 0,0634 \\
A3 & 0,1208 & 0,0822 \\
A4 & 0,0000 & 0,1529 \\
\hline
\end{tabular}

Langkah 5 : Menentukan nilai Preferensi untuk setiap alternatif

Setelah dapat nilai jarak alternatif solusi ideal positif dan solusi negatif, selanjutnya menentukan nilai Preferensi untuk setiap alternatif.. Rumus untuk menentukan nilai Preferensi menggunakan rumus (8) maka diperoleh :

$$
\begin{aligned}
\mathrm{V} 1 & =\frac{0}{0+0,1529}=0 \\
\mathrm{~V} 2 & =\frac{0,0634}{0,0634+0,1340}=0,3212 \\
\mathrm{~V} 3 & =\frac{0,0822}{0,0822+0,1208}=0,4048 \\
\mathrm{~V} 4 & =\frac{0,1529}{0,1529+0}=1
\end{aligned}
$$

Tabel 6. Nilai Preferensi pada Alternatif

\begin{tabular}{cccc}
\hline V1 & $\mathbf{V 2}$ & $\mathbf{V 3}$ & $\mathbf{V 4}$ \\
\hline 0 & 0,3212 & 0,4048 & 1 \\
\hline
\end{tabular}

\subsection{Implementasi WEB}

Pada gambar dibawah ini menampilkan kriteria pencarian untuk rekomendasi Smartphone menggunakan Merk dan Harga. Setelah melakukan pemilihan kriteria pencarian maka muncul data smartphone sesuai dengan kriteria pencarian. Pada Gambar ini dapat dilihat menghasilkan 4 jenis Smartphone. Jenis smartphone yang muncul akan dilakukan perhitungan untuk mencari rekomendasi smartphone sesuai kebutuhan konsumen. 


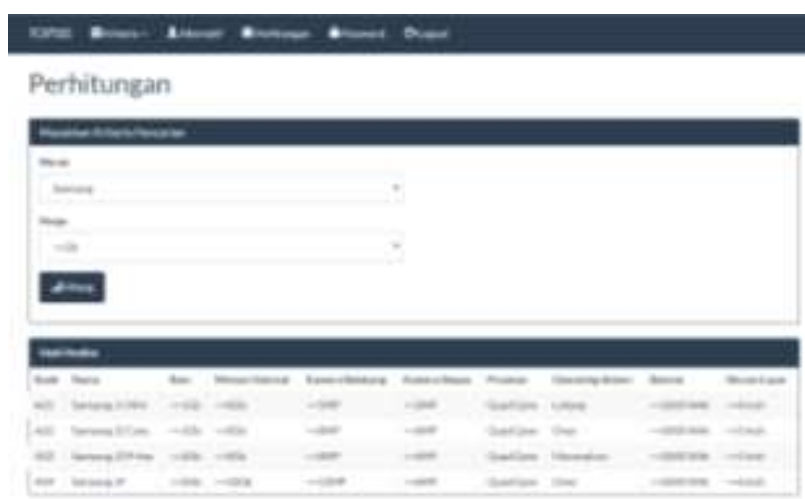

Gambar 1. Tampilan Hasil Analisa Perhitungan 1

Gambar 2. menampilkan analisa perhitungan nilai kriteria pada alternatif yang digunakan, kemudian menampilkan normalisasi dari nilai diberikan dan menampilkan normalisasi terbobot. Normalisasi terbobot didapat dari perkalian normalisasi dengan bobot yang diberikan.



Gambar 2. Tampilan Hasil Analisa Perhitungan 2

Gambar 3. menampilkan Matriks Solusi Ideal Positif dan Solusi Ideal Negatif, kemudian menampilkan Jarak Solusi Ideal Positif dan Jarak Solusi Ideal Negatif. Kemudian menampilkan nilai Preferensi dan menampilkan perankingan berdasarkan nilai Preferensi yang didapat. Gambar 4.5 dapat dilihat bahwa Smartphone Samsung J4 merupakan rekomendasi smartphone terbaik pertama berdasarkan merk Samsung dan Harga <=2 Juta dengan Samsung J2 sebagai rekomendasi smartphone terbaik kedua dan Samsung J2 Core sebagai rekomendasi smartphone terbaik ketiga.

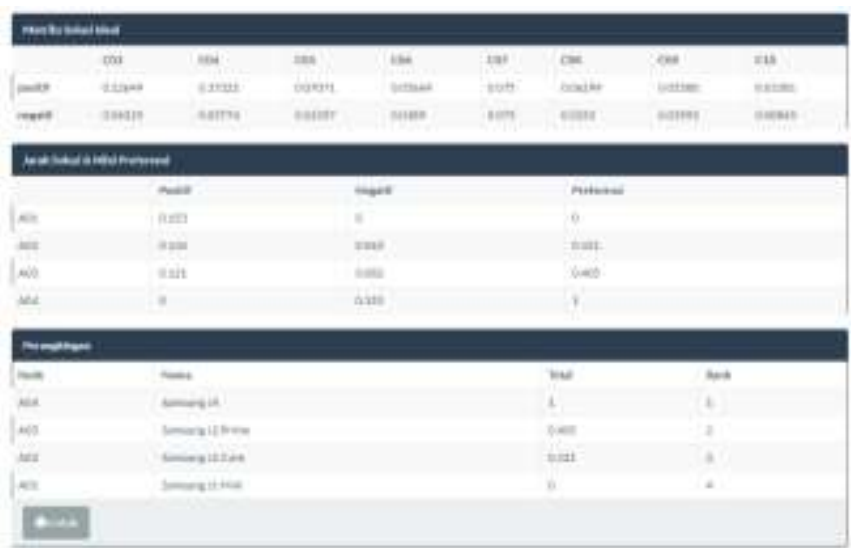

Gambar 3. Tampilan Hasil Analisa Perhitungan 3

\section{KESIMPULAN}

Setelah melalui tahap analisa dan pengujian pada Aplikasi Pemilihan Smartphone menggunakan metode TOPSIS, maka dapat disimpulkan smartphone yang terpilih sesuai dengan kriteria yang dibutuhan oleh konsumen, sistem menampilkan data smartphone berdasarkan kriteria yang digunakan. Dalam kasus, penulis menggunakan kriteria merek Samsung dan harga dibawah 2 juta. Berdasarkan kriteria yang digunakan sistem menampilkan data 
dengan kriteria yang digunakan. Penelitian ini menghasilkan rekomendasi smartphone terbaik yaitu Samsung J4 dengan nilai ranking tertinggi dan diperhitungan aplikasi nilai alternatif 1 (A04) juga yang mendapatkan nilai ranking tertinggi dimana nilai tersebut ialah 1 nilai yang dimiliki Samsung J4.

\section{REFERENCES}

[1] S. D. Prabowo And E. B. Setiawan, Jurnal Ilmiah Komputer Dan Informatika ( Komputa ), Vol. 2, No. 2, 2013.

[2] K. B. Artana, Pengambilan Keputusa Kriteria Jamak ( Mcdm ) U Tuk Pemiliha Lokasi Floati G Storage A D Regasificatio U It ( Fsru ): Studi Kasus Suplai L G, Tek. Ind., Vol. 7, No. Mcdm, Pp. 1-4, 2005.

[3] D. Nababan, R. Rahim, F. I. Komputer, U. Pelita, And H. Medan, Sistem Pendukung Keputusan Reward Bonus Karyawan Dengan Metode Topsis, Vol. 3, No. 1, Pp. 57-62, 2018.

[4] T. H. Mukti Et Al., Sistem Pemilihan Dosen Pembimbing Skripsi Dengan Metode Topsis (Studi Kasus : Pendidikan Teknik Informatika ), Vol. 4, No. 1, Pp. 53-63, 2018. 